University of Nebraska - Lincoln

DigitalCommons@University of Nebraska - Lincoln

Architecture Program: Faculty Scholarly and

Creative Activity

Architecture Program

1998

Polar Field Tent Shelters and Well-Being of Users

\author{
James Potter \\ University of Nebraska - Lincoln, jpotter2@unl.edu \\ X. Winston Yan \\ University of Nebraska - Lincoln \\ Nathan S. Krug \\ University of Nebraska - Lincoln, nkrug1@unl.edu \\ Karl C. Kuivinen \\ University of Nebraska - Lincoln \\ Marijane E. England \\ University of Nebraska - Lincoln
}

Follow this and additional works at: https://digitalcommons.unl.edu/arch_facultyschol

Part of the Architecture Commons

Potter, James; Yan, X. Winston; Krug, Nathan S.; Kuivinen, Karl C.; and England, Marijane E., "Polar Field Tent Shelters and Well-Being of Users" (1998). Architecture Program: Faculty Scholarly and Creative Activity. 15.

https://digitalcommons.unl.edu/arch_facultyschol/15

This Article is brought to you for free and open access by the Architecture Program at DigitalCommons@University of Nebraska - Lincoln. It has been accepted for inclusion in Architecture Program: Faculty Scholarly and Creative Activity by an authorized administrator of DigitalCommons@University of Nebraska - Lincoln. 
Published in Environment and Behavior 30:3 (May 1998), pp. 398-420.

Copyright ( 1998 Environmental Design Research Association; published by Sage Publications. Used by permission.

\title{
Polar Field Tent Shelters and Well-Being of Users
}

\begin{abstract}
James J. Potter holds the Douglass Professorship of Architecture at the University of Nebraska-Lincoln. He received his Ph.D. in man-environment relations from The Pennsylvania State University. He has been involved in environmental design research for more than 25 years, presenting numerous papers at professional conferences and publishing a variety of research regarding his continuing interest in how people perceive, use, and are affected by their environment. His main research goal has been to better understand the impact of change on people's health and well-being. A secondary goal has been to better understand the role the residential environment plays in people's daily lives.
\end{abstract}

X. Winston Yan is an associate professor of architecture at the University of Nebraska-Lincoln. He received his doctoral degree from the University of Michigan. He has been conducting research in areas of the built environment and behavior since the 1980s.

Nathan S. Krug is an associate professor of architecture at the University of Nebraska. He is the founder of the environmental design studio, a professional architectural firm that pursues a holistic approach to architecture. His research interests focus on energy conservation, technology as form determinant, and contextual responsibility in the built environment.

Karl C. Kuivinen is the director of the Polar Ice Coring Office and codirector of the Snow \& Ice Research Group at the University of Nebraska-Lincoln. His research interests include the general areas of polar logistics, ice drilling technology and Greenland paleoclimate reconstruction. He received his M.A. in geography/ climatology the University of Nebraska.

Marijane E. England is the assistant director of Science Support Services for the Polar Ice Coring Office at the University of Nebraska-Lincoln. Her research interests are operational research and information systems. She received her Ph.D.in community and human resources from the University of Nebraska-Lincoln.

Authors' Note: The authors are very grateful for grant support from the College of Architecture and the Office of Polar Ice Coring Research at the University of Nebraska-Lincoln. Without their support, this project would not have been possible. The authors also wish to thank the Office of Polar program at the National Science Foundation for providing the study with valuable information. 


\begin{abstract}
Polar research teams often spend extended periods of time away from base stations, living and working in remote field camps of portable tent shelters. This article reports on a study of the design and use of portable field tent shelters being deployed in Antarctica and other circumpolar areas. The purpose of the study was to determine the effect of the shelters on health and well-being of their users from an environment-behavior perspective. Preliminary analysis indicates that although the design and use of field tent shelters were generally satisfactory, there are areas in which the shelters had some adverse bearing on health and well-being of a considerable number of shelter users. This article concludes with suggestions that can be used for future design and manufacture of portable field tent shelters.
\end{abstract}

$\mathrm{T}$ he polar and circumpolar regions present a physical environment that greatly challenges human habitation. The challenge often is compounded by the very unusual social and psychological conditions: isolation, enforced small group togetherness, restricted mobility, limited communication and social contact, and the disruption of normal recreational and professional activities (Suedfeld, 1987, 1991). Surviving in the polar and circumpolar regions is a task no less difficult than surviving in undersea or space habitats.

The extreme conditions become even harsher for those who have to spend extended periods of time away from permanent research stations and laboratories, living and working in remote field camps of portable tent shelters. Depending on their research tasks, they stay in these portable shelters anywhere from a few days to as long as several weeks. The tent shelters are their only protection from the extreme physical conditions and are part of their resources for coping with the impact of the physical and social environment on their health and well-being.

Drawing results from a recently completed survey study of people who used the field tent shelters in polar and circumpolar regions over the past 5 years, this article provides a discussion of how the users' well-being is related to and sometimes affected by the design and use of portable field tent shelters. For the purposes of this study, portable field tent shelters are defined as those that are temporary and highly transportable.

Although human well-being covers a great number of issues and has many dimensions, the discussion here focuses only on those aspects of environmental psychology that have implications for the design and use of the shelters. Specifically, this article centers on the following research questions: 
1. To what extent do the design, deployment, and use of the shelters affect users' safety, health, and psychological well-being?

2. What performance factors are more important and contribute more significantly to problems, with regard to issues under investigation?

The literature search, to date, points out that the impact of the polar environment on human beings has been largely ignored or considered secondary to the real mission of polar research in the category of service (Suedfeld, 1991). Attention has been given more to the impact of human beings on the environment, such as waste disposal control and environmental protection, and less on the impact of the environment on human beings, other than the basic safety and survival issues (Oakley, 1986).

Of the literature dealing with the built environment in polar and circumpolar regions, most studies focus on either the permanent research stations or the large, semipermanent structures (ASA, 1991; Brier, 1969; Flanders, 1980; Floyd, 1974; Johnson, 1970; Kovacs, 1981; Ledingham \& Keage, 1986; NCEL, 1991; Richter, 1979). Much less information is available on the small, portable field structures transported on a sled, usually behind a snowmobile (Chinn, 1983). The available literature related to portable shelters is often 10 to 20 years old, and some shelters were reviewed in recreational camping magazines that often lacked a systematic approach.

It also was revealed in the literature review that studies of field tent shelters from the psychological and physiological perspectives of their users tend to focus more on training for adaptation to the harsh conditions and the isolated and confined environments (ICES) (Carrere, 1990; Mocellin \& L Suedfeld, 1991; Natani \& Shurley, 1979; Suedfeld, 1991). Relatively little has been written regarding the impact of the tent design on the health and well-being of its occupants living in small tent shelters in remote field camps under extreme climatic and social conditions for an extended period of time.

Palinkas (1991) was one of the few to study the effects of physical and social environmental stressors on the short-term and long-term health and well-being of Antarctic winter-over personnel who stayed in a number of permanent stations. The study revealed that station size and severity of physical environment were significantly inversely associated with symptomatology of the winter-over syndrome.

In a study to confirm suggestions of anecdotal evidence that personnel in isolated, polar work settings experience a sharp decline in motivation and morale shortly after the halfway point of their mission - that is, the "third-quarter phenomenon" - Steel and Suedfeld (1991) suggested that individual arousal may be related to length of isolation and interactively affected by significant events and people's expectations regarding the duration of their stay. 
Carrere and Evans (1994) discovered design qualities of the built environment that are important to psychological well-being of people in ICEs. The qualities included the need for privacy, flexible and novel behavioral settings, freedom to personalize the setting, and distinct work, recreational, and soundproof multifunctional personal spaces for sleeping and other individual uses as personal refuge. According to their study, the physical confinement associated with ICEs may heighten the need for privacy and for personal territory. Failure to provide adequate space for personal needs, sleeping, working, and leisure activities can lead to low morale and fatigue.

Another limitation of the previous studies resides in research methodology. There is relatively little to be found in the literature that took a systematic postoccupancy evaluation (POE) approach to better understanding design and use of the various types of portable shelters. As a proven, effective means of researching environment and behavior interaction from a user perspective (Marans \& Spreckelmeyer, 1981; Preiser, Rabinowitz, \& White. 1988), a POE study of the shelters is essential to make the shelters not only a protection for survival but also an environment promoting users' well-being.

\section{Method}

Data collection for the study involved two steps. First, a telephone interview of selected polar researchers was conducted to identify issues pertinent to the investigation. The interview addressed issues concerning both performance of the shelters and psychological well-being of users as affected by the design and use of the shelters. Second, built on the initial telephone interview, a more inclusive, less open-ended mail-in survey questionnaire was developed. The questionnaire was pretested with several shelter users on the campus of the University of Nebraska-Lincoln who had been to polar and circumpolar regions many times. Input from the pretest was integrated into the final version of the questionnaire. The telephone survey was conducted during the months of September and October 1995, and the mail-in survey was carried out from January through March 1996.

\section{Procedure}

Study participants for the telephone interview and the subsequent selfadministered questionnaire survey were identified from a pool of candi- 
Table 1. Experience of Survey Respondents

\begin{tabular}{|c|c|c|c|c|}
\hline $\begin{array}{l}\text { Polar and } \\
\text { Circumpolar Sites }\end{array}$ & $\begin{array}{l}\text { Number of } \\
\text { Respondents } \\
\text { Who Went } \\
\text { There }\end{array}$ & $\begin{array}{c}\text { Total Number } \\
\text { of Times Gone } \\
\text { There Over } \\
\text { the Years }\end{array}$ & $\begin{array}{c}\text { Total Number of } \\
\text { Weeks Stayed } \\
\text { There Over } \\
\text { the Years }\end{array}$ & $\begin{array}{l}\text { Median } \\
\text { (weeks) }\end{array}$ \\
\hline Antarctica & 74 & $1-26$ & $1-180$ & 25.0 \\
\hline Greenland & 28 & $1-10$ & $1-70$ & 15.0 \\
\hline Alaska & 31 & $1-40$ & $1-260$ & 15.5 \\
\hline $\begin{array}{l}\text { Others (Siberia } \\
\text { and Iceland) }\end{array}$ & 8 & $1-6$ & $1-20$ & 8.5 \\
\hline
\end{tabular}

dates who went to Antarctica and other circumpolar regions and used field tent shelters in the past 5 years. The pool of candidates was generated using information from the Office of Polar Programs at the National Science Foundation (NSF) and the Polar Ice Coring Office at the University of Nebraska-Lincoln. A sample of 30 scientists of the pool was selected for the telephone interviews, and more than 200 were identified to receive a copy of the self-administered mail-in survey questionnaire. In total, 16 people were interviewed by telephone and 106 returned the survey questionnaire.

Table I presents the statistics of the survey respondents with regard to their overall experience in the polar and circumpolar regions. It should be noted that many went to more than one polar and/or circumpolar area and engaged in more than one trip. As indicated in Table 1, some had gone to those areas for as long as 260 weeks (cumulatively) over several years.

\section{Measures}

The mail-in survey questionnaire is composed of five sections. The first section collected general background information about respondents' experience with different types of tent shelters in different polar and circumpolar areas. The second section asked information relevant to the climatic and weather conditions respondents encountered while in those polar and circumpolar regions. The third section covered data pertinent to physical aspects of the field shelter such as size, tent door types, materials, colors, insulation, ability for personalization within tent shelters, air quality, humidity, moisture buildup, noise conditions, and so on. The fourth section dealt with use of the field shelter. The final section included questions regarding the influence of design and use of the tent shelters on users' sense of well-being. In total, more than 150 questions were included in the questionnaire, of which a majority used a structured, closed-ended format. 
To study the impact of the design and use of tent shelters on users' well-being, some data collection techniques used by several studies of environmental psychology were adopted as a reference (Byrne, Barry, $\mathcal{E}$ Nelson, 1963; Derogatis, Lipman, Rickels, Uhlenhuth, \& Covi, 1974; Leon, 1991; Mackay, Cox, Burrows, \& Lazzerini, 1978; Ursin et al., 1991). These studies all used self-descriptive questionnaires as instruments to explore various aspects of psychological well-being such as mood, stress, depression, and anxiety. Although this research addressed issues in great depth and detail from a perspective of clinical psychology, our study used part of their well-being measurements in a more modest way. Only those items relevant to, and potentially with implications for, the design and use of the field tent shelters were included in the questionnaire. 'The interitem reliability (Cronbach's alpha) was .81 among the five variables used to measure well-being - that is, loneliness, depression, nervousness, restlessness, and weakness - and was .72 when additional measurements of feeling frustrated, challenged, and threatened, and having sleeping problems were included.

\section{Analysis}

Although the study aimed at evaluation of the tent shelter by the entire sample population, it also took a comparative approach in data analysis to see if any variations exist among the different types of field tent shelters. Three categories of tent shelters were defined for the purpose of data analysis. The first was the small, Scott and Arctic Oven type tents (abbreviated as S\&A hereafter), which usually are used by one, two, or up to four people. The second category included all other small tent shelters, such as Dome and North Face VE25 types of tents (abbreviated as D\&N hereafter). The last group was for the relatively larger, semipermanent types of tent shelters such as the Jamesway and Polarhaven (abbreviated as J\&P hereafter). Samples of tent types appear in Figures 1 through 4.

There were two reasons to divide the small tent shelters into the two categories - the S\&A and the D\&N. First, it became clear to the investigators that the Scott-type tent shelters, although one of the oldest types, were still the most commonly used in field camps for accommodating up to four people. The relatively new Arctic Oven-type tent shelters have become popular in recent years. Their abundant use and similar functions make them reasonable to be singled out for an extensive evaluation study. Second, slightly more than one third of the respondents responded to the survey based on their experience with the S\&A type tent shelters, and another one third based responses on the D\&N tent shelters. This fact made the grouping a viable strategy for conducting comparative statistical analysis. 


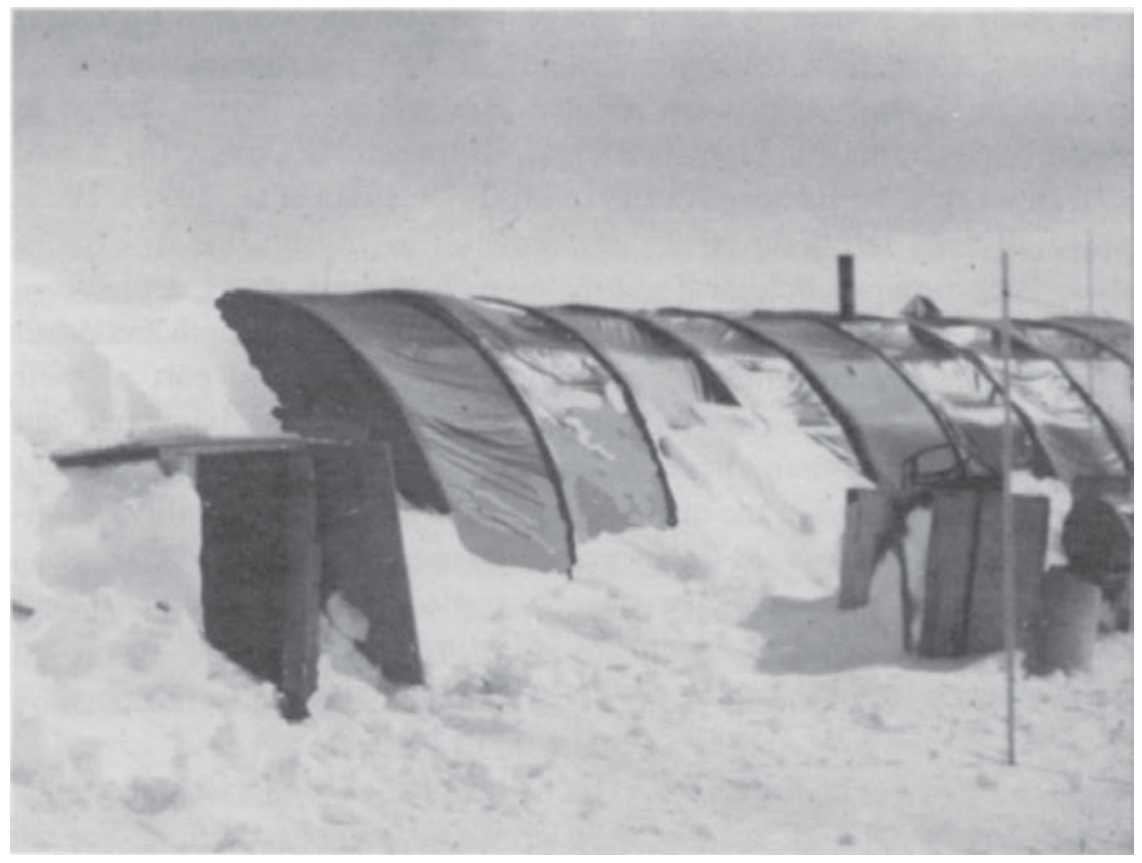

Figure 1. Scott Tent

Including the relatively large and semipermanent shelters of J\&P types in the study was compelled by two considerations: their abundant use in field camps and their design and use features that were distinctly different from those of the smaller tents. Having this group allowed the data analysis to see how significant the difference is between evaluations of the smaller and larger tent users with regard to issues of safety, health, and well-being, as well as seeing what could be learned from each type to improve designs and use of the shelters.

\section{Results and Discussion}

\section{The Built Environment}

Data of this study indicate that respondents had a generally positive overall evaluation of the shelters currently used by American polar researchers and other support personnel. Table 2 gives a general evaluation of the various types of field shelters based on respondents' overall experience with the shelters over the years. It should be noted that many re- 


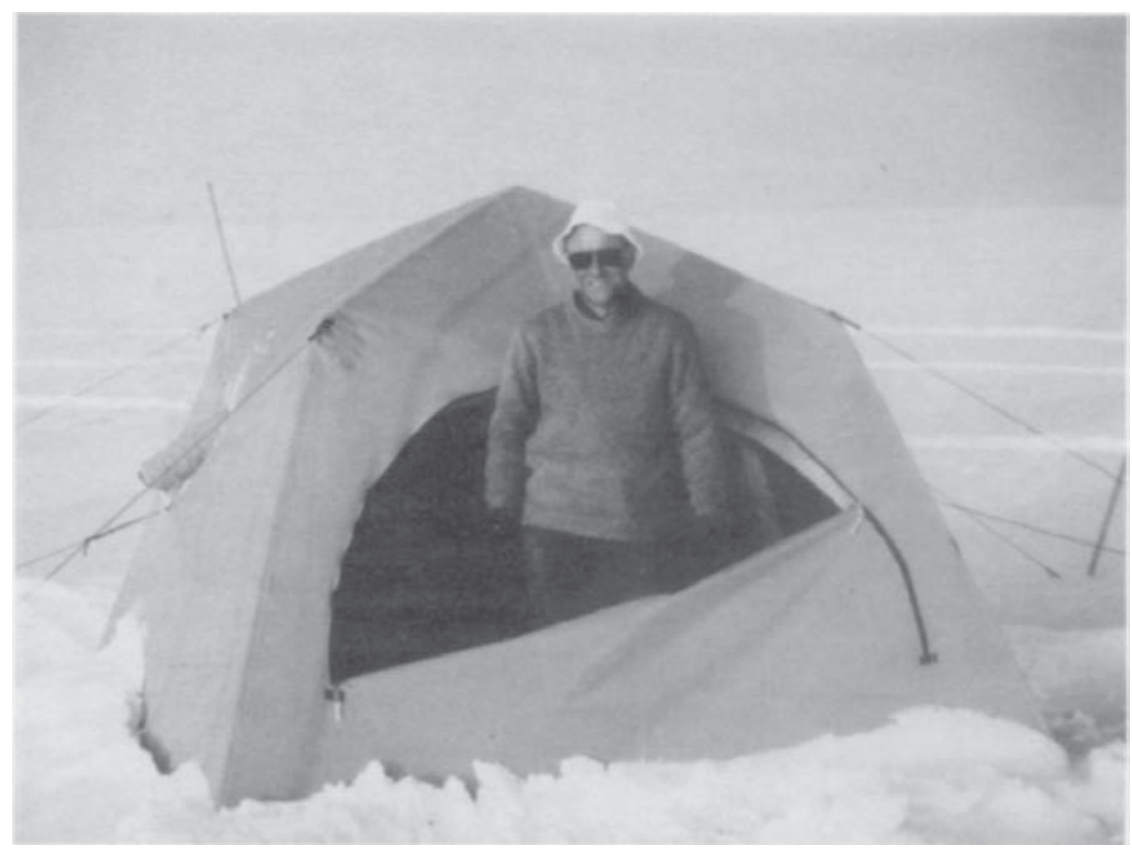

Figure 2. Weather Haven Tent

spondents in this study had used more than one type of tent shelter and had gone to more than one region over the years, as indicated in Table 2.

Although the overall evaluations of the shelters were generally positive, further analysis of various aspects of the design and use of the shelters does tend to suggest that users experienced problems in some areas and improvement is needed.

Noise

The data of this study indicated that noise apparently was very problematic with all types of tent shelters studied. As indicated in Figure 5, noise was rated poorly by users of all three tent groups. Although the noise problem is predictable considering the thin fabric layers (with little sound-insulative property) of the tent shelters, noise coming from wind and the slapping sound of tent materials during windy days caused a serious sleeping problem with many people. As mentioned by a number of the respondents, "it [wind] made enough noise to interrupt my sleep" and "it was too loud, like thunder or a hurricane passing by." For users 


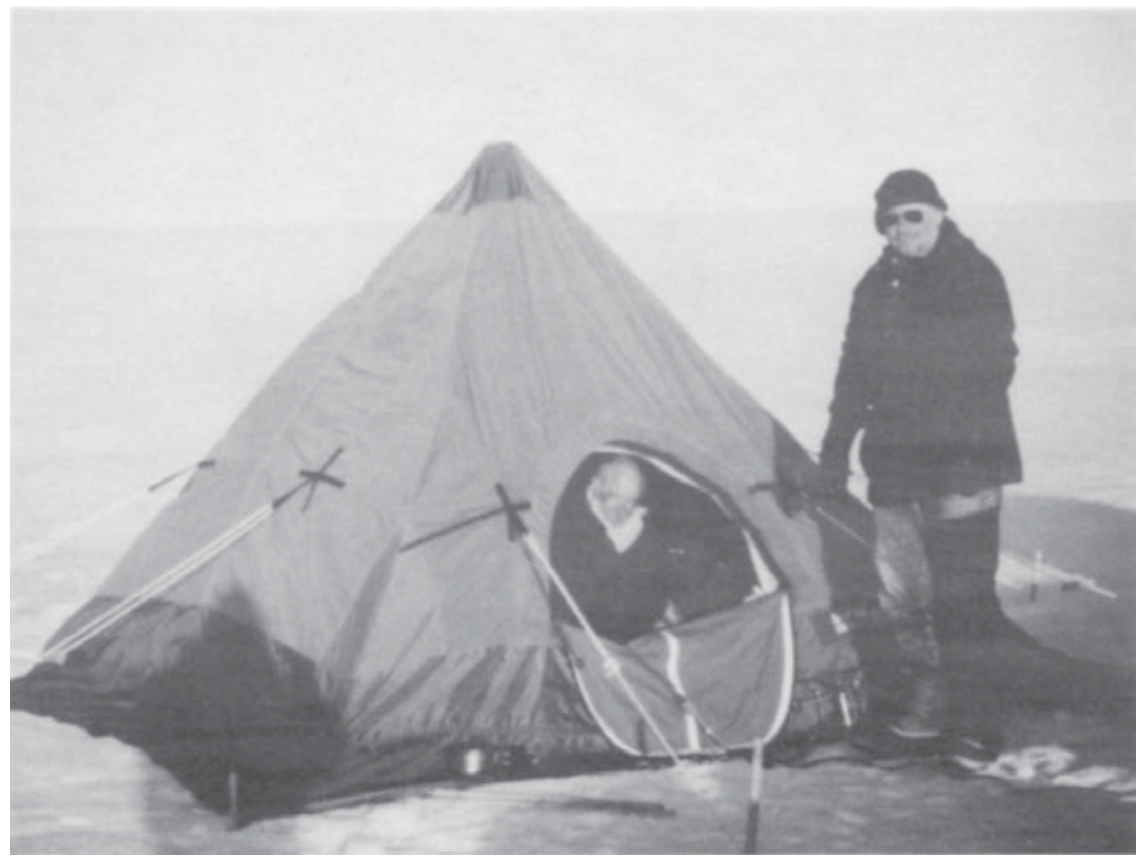

Figure 3. Jamesway Tent

of the J\&P tent shelters, the problem of wind was further compounded by human noise resulting from multiple occupancies in the tent shelters. This in fact made the J\&P shelters the most problematic and rated poorest among the three tent groups with regard to noise conditions inside tent shelters.

\section{Air Quality}

Air quality inside tent shelters was another area that varied among users of different types of tents. As indicated in Figure 6, although the mean scores of the evaluation by all three groups were on the positive side, the number of those who complained was not insignificant. Among them, J\&P users felt there were more problems with the air quality than the other two groups. The difference is quite significant. Information gathered in the telephone interviews and from responses to some openended questions of the survey tends to suggest that this might be largely a result of the fact that J\&P tents had a large number of occupants and there was generally a lack of means of naturally ventilating them, such as operable windows or mechanical ventilation. 


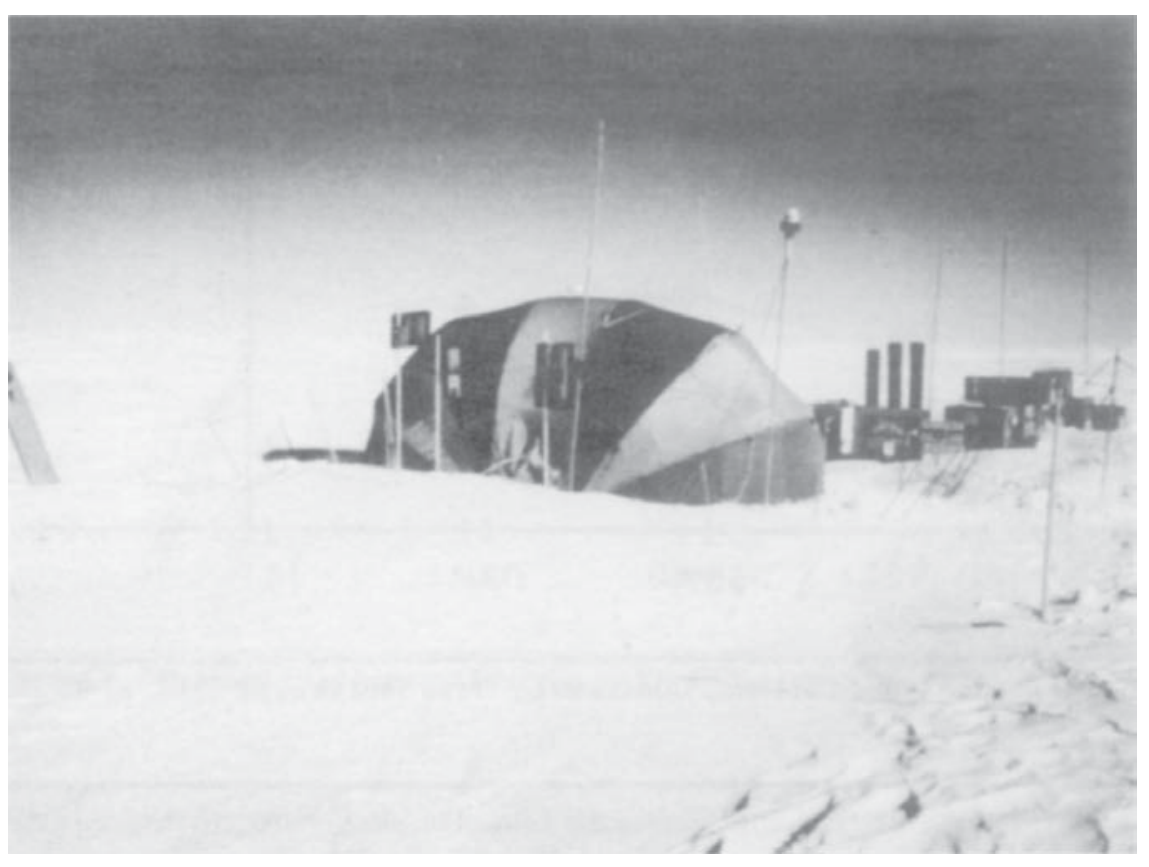

Figure 4. Arctic Oven Tent

Table 2. General Evaluation of Field Tent Shelters

\begin{tabular}{lccc}
\hline Types & $\mathrm{M}^{\mathrm{a}}$ & Number of Respondents & $\mathrm{SD}$ \\
\hline S\&A types & & 57 & \\
$\quad$ Scott tent & 3.0 & 13 & 1.03 \\
$\quad$ Arctic Oven & 3.2 & & 0.90 \\
D\&N types & & 15 & 0.80 \\
Dome tent & 2.9 & 24 & 1.06 \\
North Face VE25 & 2.9 & 12 & 1.17 \\
North Face (others) & 3.1 & 24 & 0.92 \\
$\quad$ Other types of small tents & 3.2 & & 0.86 \\
J\&P types & & 43 & 0.88 \\
$\quad$ Jamesway & 2.9 & 13 & \\
Polarhaven & 3.5 & & \\
\hline
\end{tabular}

a. Means are based on a 4-point scale with $1=$ most negative and $4=$ most positive. 


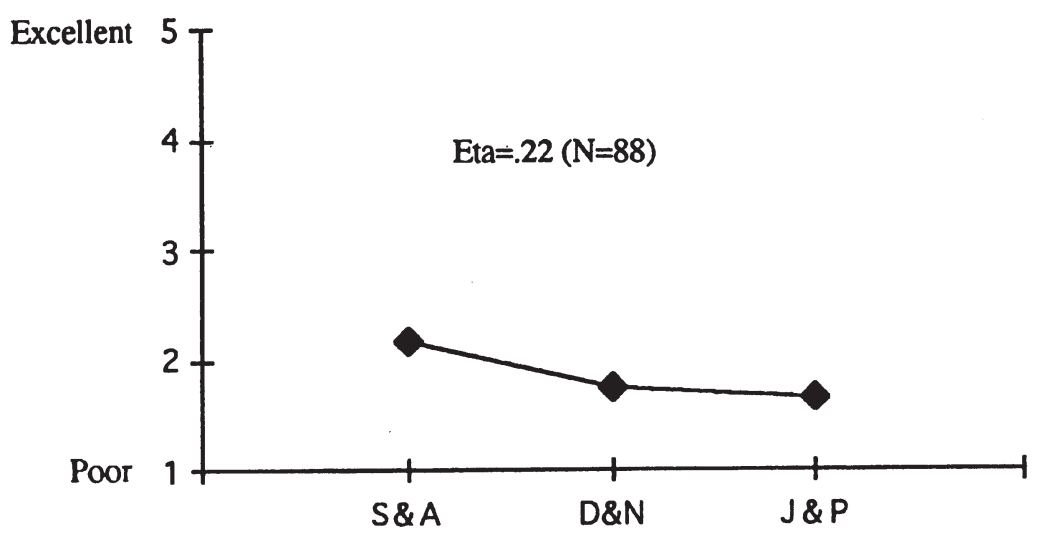

Figure 5. Evaluation of Noise Condition by Three Tent Groups

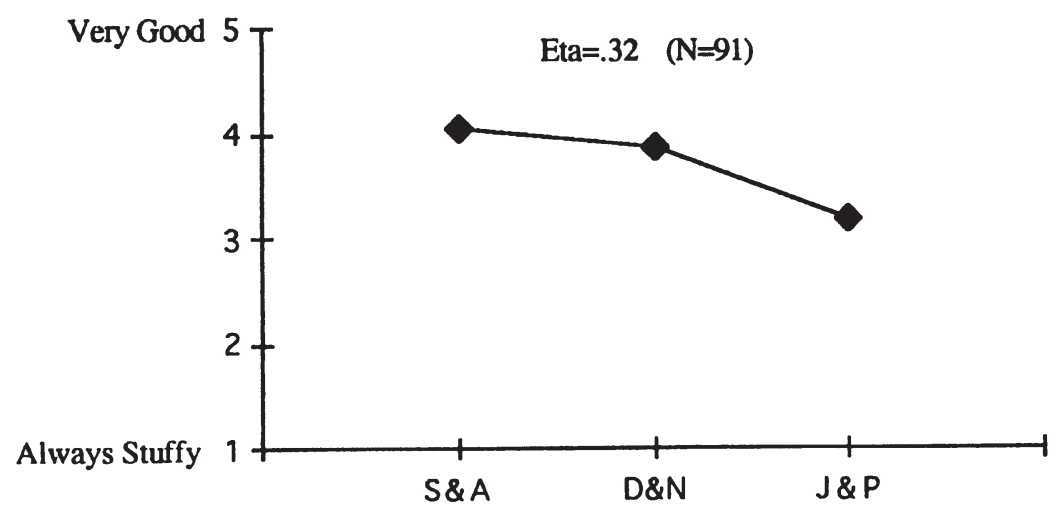

Figure 6. Evaluation of Indoor Air Quality by Three Tent Groups

\section{Humidity}

Extremely cold temperature in the polar and circumpolar regions results in low relative humidity, which becomes a problem for many people. According to the data, slightly less than half of them $(42 \%)$ said the air inside tent shelters was much too dry. Among the three tent groups, J\&P users seemed to have the most serious problem, as indicated in Fig- 


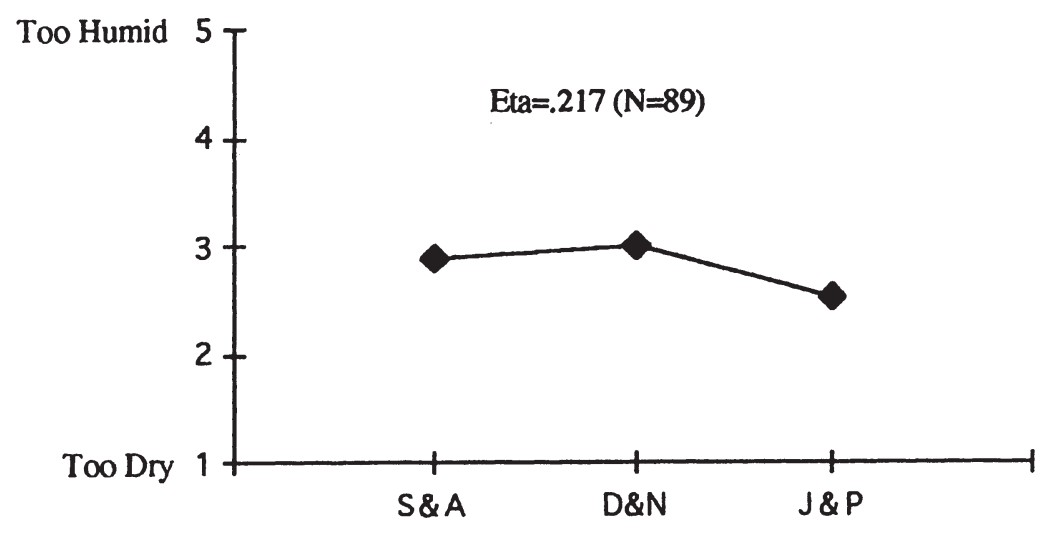

Figure 7. Evaluation of Indoor Humidity by Three Tent Groups

ure 7. Use of auxiliary heating systems, often without humidifiers, inside the J\&P tent shelters might have contributed to the low evaluation rating of the J\&P tents.

The low humidity apparently helped reduce problems related to indoor moisture buildup, which can be a problem under normal climatic conditions because of the high fabric density of tent materials. Only about $14 \%$ of the S\&A tent users, $23 \%$ of the D\&N users, and $20 \%$ of the J\&P users experienced problems with moisture buildup inside tent shelters. The evaluation of moisture buildup inside the tent shelters became different when cooking inside the shelters was considered. Although moisture generated in cooking was not a concern for about two thirds of the users who cooked almost daily, about one third did experience the problem. Some respondents even commented that the situation was as serious as "raining."

\section{Temperature}

Evaluation of the field tent shelters with regard to their indoor temperature shows a relatively less problematic situation and the least variation among the three groups, as indicated in Figure 8. Although the tent shelters provided 21 generally acceptable day and night temperature inside the tent shelters, the dramatic fluctuation in temperature between day and night in the polar and circumpolar areas apparently presents some problems with inside day temperature. For example, about $31 \%$ of the D\&N tent users and $41 \%$ of the J\&P tent users felt that daytime temperatures were somewhat too warm. According to 


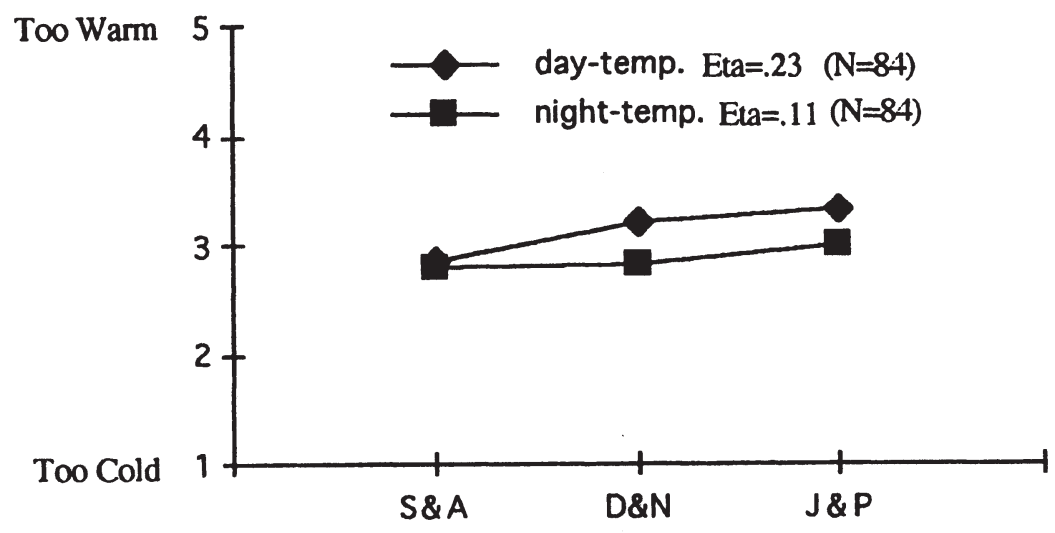

Figure 8. Evaluation of Day and Night Temperature by Three Tent Groups

some survey respondents, the daytime temperature inside tent shelters could become fairly warm because of well-insulated tent fabrics. In some circumstances, an operable window in the tent wall would be desirable to alleviate this problem.

\section{Material and Color}

The fabric density of tent shelters, as one of the most important design and manufacture issues, was found to contribute to a certain level of dissatisfaction and some problems. As indicated in Figure 9, although user evaluations of moisture blockage by tent fabrics did not vary significantly among the three groups, the light blockage of the S\&A and D\&N tent shelters was rated significantly poorer than that of the J\&P tents. Between the $S \& A$ and $D \& N$ tent groups, the latter was rated even poorer than the former in terms of cold air and light blockage.

The failure of the tent shelters in blocking daylight had significant adverse effects on the well-being of shelter users. Because most of the polar and circumpolar regions have an extreme light-to-dark cycle, the ability of tent shelter materials to block light at "night" is of vital importance to sleeping. In fact, a large number of respondents reported sleeping problems because of the insufficiency of tent fabrics in preventing bright light 


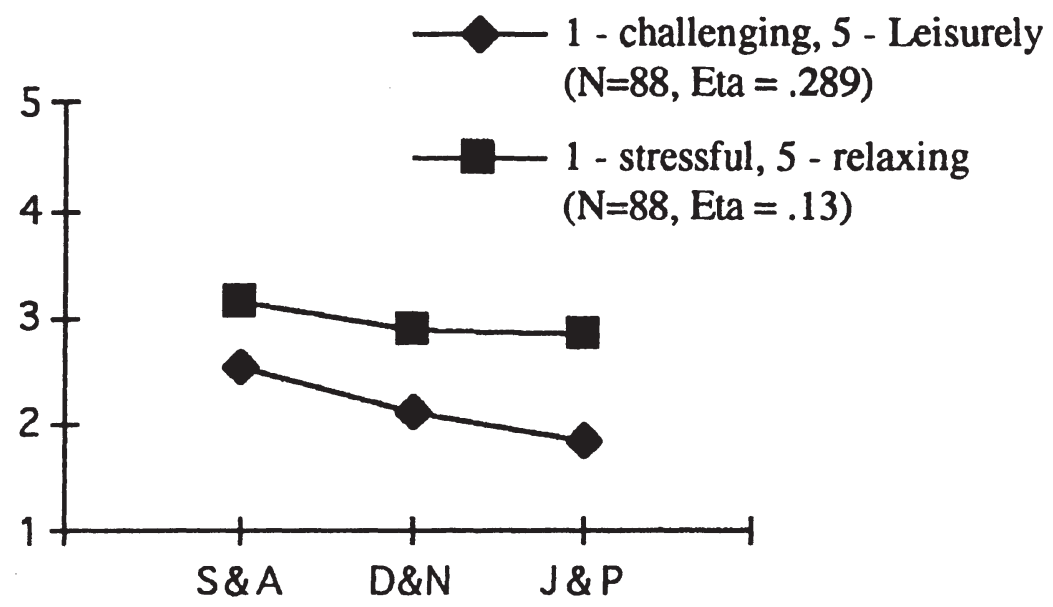

Figure 9. Evaluation of Air, Light, and Moisture Blockage by Three Tent Groups

from entering into tent shelters. However, one should be cautioned that light blockage by tent materials may cause another indoor lighting problem. Many also mentioned in the survey that dark interiors often made it impossible and inconvenient to even find flashlights, let alone to do other things. Some respondents also mentioned that maintaining a certain level of light inside the shelters made it possible to perform other activities such as reading and writing letters, instead of just sleeping. This suggests that the design and manufacture of the portable tent shelters should be dark on one hand, for sleeping, and have some light on the other hand, for people to see. Apparently, use of appropriate materials alone may not meet the conflicting needs. Appropriate design of doors and windows may provide alternatives.

Responses to this study tended to suggest that exterior and interior colors seemed to be another factor affecting the overall evaluations of tent shelters. For the S\&A tent users, overall satisfaction with the tent was somewhat related to the exterior and interior materials $(R=.41$ and .34 , respectively), but not to exterior and interior colors ( $R=.19$ for both). For the D\&N tent shelters, overall satisfaction was closely related to exterior and interior colors $(R=.44$ and .41 , respectively) and tent exterior $(R=.42)$ and interior $(R=.48)$ materials. For the J\&P users, overall satisfaction with the structure was very highly related to its interior materials $(R=.77)$ and interior colors $(R=.73)$, followed by exterior colors $(R=.54)$ and exterior materials $(R=53)$. 


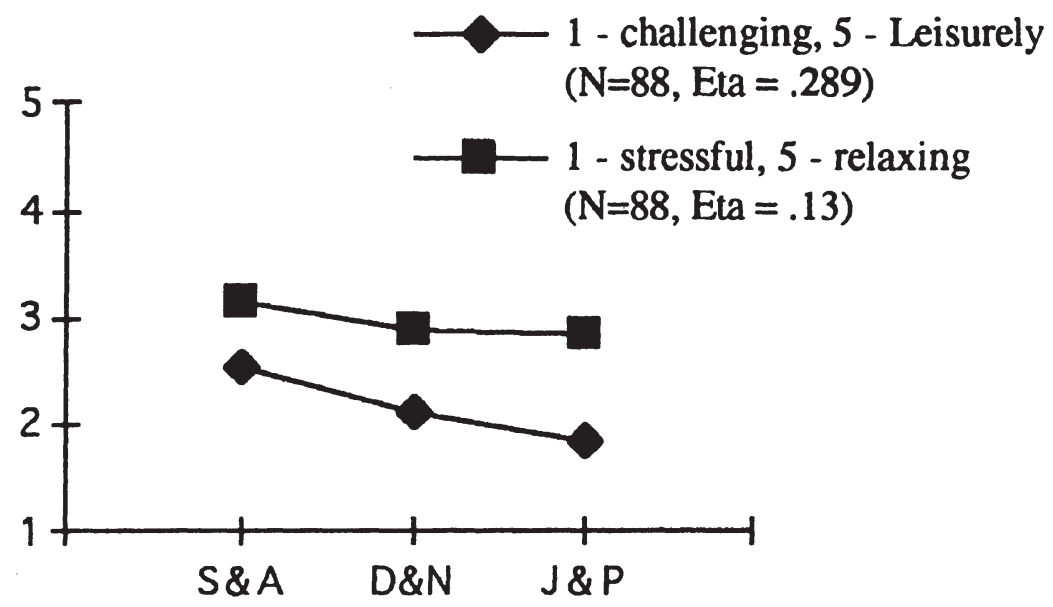

Figure 10. Ratings of Life in Field Camps by Three Tent Groups

\section{Well-Being of Users}

Contrary to a popular view and some anecdotal evidence that people in the isolated. extreme polar environment endure a high level of stress as well as a negative effect on their well-being, findings of this study tended to suggest that although life at remote field camps was somewhat stressful, it was not aversive (see Figure 10). In fact, many found their life at the field camps was, although somewhat challenging, not too stressful. High task motivation as well as unusual scenic landscape might help avert the negative effects of stress on people.

Because safety is of utmost importance in the design and use of field tent shelters, the survey made in-depth probes to learn how users evaluated tent shelters with regard to safety. Although this study did not discover any alarming facts, several aspects of the responses seemed to suggest that concerns about safety among the users were not insignificant, and variations in evaluations of different types of shelters are worth noting.

The shelters used by respondents of this survey seemed to have performed generally well in providing protection from the extremely harsh climatic conditions and in withstanding high winds and blowing snow. As a result, only $9 \%$ of the respondents said they were somewhat concerned about their safety during severe weather. Certain noteworthy variations, however, did surface. Although none of the J\&P users and $6 \%$ of the S\&A tent users had concerns about their safety under severe weather, about $18 \%$ of the D\&N tent users did. This differ- 
ence was further revealed by other facts. When asked whether their tent had ever failed to provide protection because of harsh weather conditions, only $9.5 \%$ of the S\&A tent users reported experiencing such a failure, as opposed to about $44 \%$ of the D\&N tent users, who reported experiencing problems at least once. Apparently, the S\&A type tent shelters were much better able to resist harsh weather than the others. The failures were caused by many factors, such as bent poles, fabric rips, leaking, poor ventilation, snow drifting, hosting inside, broken braces caused by snow buildup, and broken doors. Some tent shelters were completely destroyed by high wind.

Although much attention regarding human safety was generally focused on harsh weather. the results of this study indicate that there was also a concern for fire safety among a considerable number of users. Although our study indicated there was only one occasion in which a fire accident actually occurred in a tent shelter, and therefore the concern about fire safety seemed more perceptual, concern in the minds of users certainly would adversely affect their well-being.

The data indicated that about $23 \%$ of the S\&A tent users, $43 \%$ of the D\&N tent users, and $35 \%$ of the J\&P tent users had a certain level of concern about fire safety. The percentages are certainly not so small as to be ignored. What is more interesting is the fact that fire safety was a greater concern among a large percentage of tent users who used various types of heating systems and/or did extensive cooking inside their tent shelters. For example, among those who used auxiliary heating systems on a daily basis, about $36 \%$ were concerned about fire safety. Similarly, among those who cooked inside tent shelters almost daily, about 38\% said they were concerned about fire safety. In fact, some of the respondents mentioned that they constantly kept a fire extinguisher and sharp knives handy in case of fire emergency. The concern is worth noting in view of the fact that using an auxiliary heating system and cooking inside tent shelters were very common. The data of this study show that about $38 \%$ of the respondents used an auxiliary heating system inside their tent shelters almost every day, and $35 \%$ of them cooked almost daily, with a majority of them $(70 \%)$ using gas stoves for cooking.

One of the interesting findings related to safety and health concerns oxygen depletion because of cooking inside tent shelters. Among the respondents who cooked extensively, $37 \%$ of the S\&A tent users said they were concerned about the depletion. Only about $14 \%$ of the D\&N tent users and $17 \%$ of the J\&P users shared the same concern. Although both the S\&A and D\&N types arc small tent shelters, the significant difference between them warrants further probing. One possible explanation of the difference may be related to the design of doors and windows of the shelters. Some had operable windows that allowed fresh air to come in. 
To better understand well-being of tent users, the study examined some aspects of well-being suggested by anecdotal evidence and early studies to be problematic because of the extreme polar environmental or social conditions. Some of the preliminary findings with regard to this issue are discussed below.

First, a lack of privacy was a problem experienced by users of all types of shelters, although the magnitude of the problem varied quite significantly among them. The large J\&P structures were rated negatively in terms of a lack of privacy by $85 \%$ of their users, as opposed to $23 \%$ of S\&A tent users and $33 \%$ of D\&N tent users. The lack of privacy for J\&P users apparently remains a problem even though many J\&P tent shelters have incorporated interior partitions since 1988. The issue of privacy was considered important and essential to the mental health of people in a field camp situation as indicated by data and written comments of this survey.

Second, the J\&P tent users apparently had much greater problems sleeping inside tent shelters than did users of the other two types. About $30 \%$ of the J\&P users said they frequently had trouble getting to sleep, as opposed to $10 \%$ ) of the S\&A and $20 \%$ of the D\&N tent users. It also was found that the sleeping problems of many were attributable to a number of well-being issues. Among them were a feeling of restlessness $(R=.57)$ and nervousness $(R=.24)$.

Third, providing certain means of personalization inside the tent shelters seemed to be of great importance to the users because, according to this study, slightly more than half $(51 \%)$ of the respondents did some sort of personalization. It also was found that being able to personalize the space was fairly closely related to the overall satisfaction with the tent shelters $(K=.44)$. Some used pockets on interior sides of shelters, and others added cots and small shelves for storage, tables of boxes, dividers (when shared by two), and ropes to hang wet socks or to suspend reading lights.

Fourth, although a majority of the users felt that the design of the tent did not negatively affect their mood and sense of well-being, about $18 \%$ of them felt that the design of tent shelters affected their performance. The negative effect seemed to be attributable to a number of design and use factors of the shelters, such as lack of privacy, color, space restrictions, bright light at night, noise conditions, stability, and temperature control, as mentioned by a number of respondents.

Fifth, the results of this study indicate that a feeling of depression was highly related to a feeling of loneliness among users of all types of the tent shelters $(R=.72$ among the S\&A tent users, $R=.74$ among the D\&N tent users, and $R=.66$ among the J\&P tent users). In addition, depression 
was also related to problems with sleeping $(\mathrm{R}=.48$ among the S\&A tent users and $R=.51$ among the D\&N tent users).

Sixth, the isolation and confinement that people experienced at remote camps of small tent shelters become most serious when they are confined in the shelter during severe weather conditions. A considerable amount of users (28\%) felt that their mood was adversely affected when they were confined. Among the three tent groups, the S\&A lent users felt most affected. About 39\% of the S\&A tent users indicated the feeling, as opposed to $17 \%$ of the D\&N tent users and $25 \%$ of the J\&P tent users.

According to data of this study (see Figure 11), the most popular activity under the severe weather condition seemed to be reading novels among users of all three types of shelters. Very few listened to the radio. What is interesting is that although it was hypothesized that activities people engaged in would differ between those who stayed in small S\&A and D\&N tent shelters and those who stayed in large J\&P tents because of different physical and social settings, the results as presented in Figure 11 did not support the hypothesis. The percentage of people who read and wrote in small shelters was not greater than that of those in large ones. Nor was the percentage of card playing among the J\&P users greater than among those living in the small shelters, although one might expect otherwise because there were more people inside J\&P shelters.

To find out what aspects of the design and use of the shelters were most important in predicting the satisfaction of users and how much each of them contributed to explaining the variance in the well-being measures such as depression, several linear regression analyses were conducted. As shown in Table 3, the analysis was done with regard to selected factors in three groups individually. Of the selected physical predictors, ratings of the ability to personalize space seemed to be the most important predictors of the user satisfaction. Next in line were ratings of interior colors, the sufficiency of tent materials in blocking light, fabric materials of interior layers, and finally the materials of exterior layers. The data of this study also indicated that neither the size nor the height of tent shelters appeared to be an important factor affecting people's overall satisfaction with tent shelters. Altogether, the five physical predictors accounted for $19 \%$ of the variation in respondents' satisfaction.

Of the selected six psychological factors, the one that measured how the design of the tent shelter affected users' mood became the most important predictor. Feeling restless and sleeping problems were two other important predictors. The six factors were able to explain $13 \%$ of variance in the user satisfaction with the tent shelter. What is more interesting is 


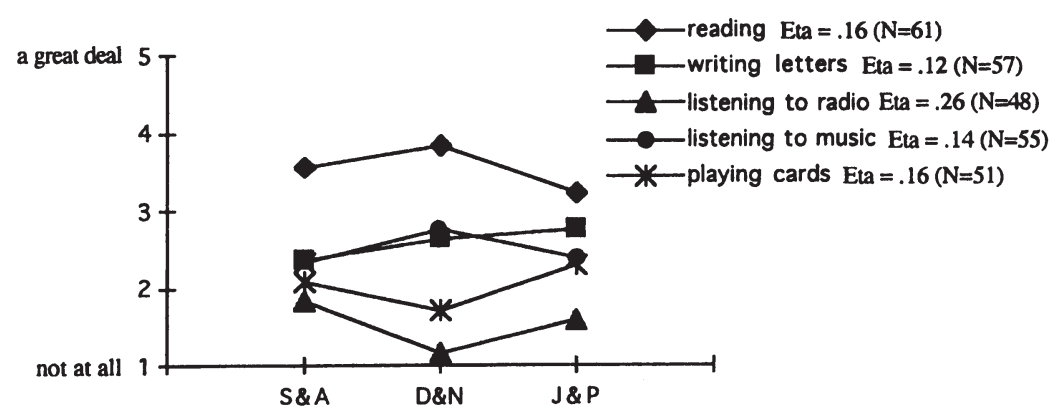

Figure 11. Mean Scores of Activities by Three Tent Groups

Table 3. Satisfaction Predicted by Ratings of Selected Physical, Environmental, and Psychological Aspects of the Shelters

Physical

Ability to personalize space $.34(1)$

Interior colors $.20(2)$

Light blockage by tent fabrics

Materials for interior layer

Materials for exterior layer

Ambient environmental

Humidity inside tents

Indoor air quality

Night temperature

Day temperature $.06(4)$

Psychological

Mood affected by tent design

Restlessness

Sleeping problems

Nervousness

Loneliness

Privacy

Percentage of variance explained (multiple adjusted $R^{2}$ )

Note. Numbers in parentheses indicate ranking of importance. 
Table 4. Depression Predicted by Ratings of Selected Psychological Aspects

\begin{tabular}{ll}
\hline Predictors & Beta Coefficients \\
\hline Psychological & $.55(1)$ \\
Loneliness & $.21(2)$ \\
Sleeping problem & $.16(3)$ \\
Feeling bored & $.15(4)$ \\
Nervousness & $.07(5)$ \\
Satisfaction with the shelters & .54 \\
Percentage of variance explained (multiple adjusted $\left.R^{2}\right)$ & \\
\hline
\end{tabular}

Note: Numbers in parentheses indicate ranking of importance. $N=84$.

the fact that the ambient environmental factors apparently contributed very little $(3 \%)$ to the prediction of user satisfaction with tent shelters, as indicated by the value of adjusted $R^{2}$.

Similarly, Table 4 shows results of regression analysis of depression predicted by selected psychological factors. As indicated, the five factors combined accounted for $54 \%$ of variance explained. Of the five factors, the feeling of loneliness was the most important predictor of a feeling of depression by the users of tent shelters. Problems with sleeping was the second most important predictor.

\section{Conclusion and Limitations}

Extreme environmental and social conditions in polar and circumpolar regions present great challenges to human beings living and working there. The conditions are much harsher and the challenge is much greater for those who spend an extended period of time at remote field camps of portable tent shelters. The shelters are the only built environment available to alleviate the harshness of the natural environment and ensure the users' well-being. Although high task motivation and an unusual scenic landscape help them adapt to the harsh conditions with few complaints, this study has found a number of areas where health or the sense of wellbeing for the people at remote camps were adversely affected as a result of a combination of' harsh natural environment and the built environment. Many of those areas have some implications for design and use of the tent shelters. The fact that problem areas varied from one type of tent shelter to another makes the findings of this study more noteworthy. 
A concern for safety in the minds of a considerable percentage of users of the field tent shelters is worth noting. Its adverse effect on the wellbeing of the users should not be overlooked. Some of the safety concerns were attributable to harsh weather, whereas others were related to fire. The level of concern for fire safety was significantly increased when using auxiliary heating systems and cooking inside the tent shelters. This concern certainly did not help ensure the psychological well-being of the shelter users. It should be addressed in the future design of shelters and in training of users prior to going into the field.

Recognizing the vital importance of the tent shelter as the key element of the built environment in protecting lives and providing healthy, habitable conditions, this study examined several aspects of environmental quality that are relevant to the design and use of the shelters. Some issues surfaced in areas of day and night temperatures, humidity, noise conditions, air quality, and oxygen depletion inside tents. Although problems related to these issues seem to be inevitable under the extreme polar climatic conditions, the magnitude of their negative effect on users' well-being can be modified and reduced through improved design and use of tent shelters.

The data also indicate that a considerable percentage of respondents felt that the design of the tents adversely affected their performance, mood, and well-being, and had an effect on certain adverse symptoms such as sleeping problems, depression, and loneliness. The negative impact on their wellbeing seemed to be attributable to factors such as fabric colors, space restrictions, tent stability, temperature control, lack of privacy, fire and weather safety, and a lack of means for personalizing space. Such feelings also contributed to depression among some of the users.

The last but not the least lesson learned through this project is that although a majority of users of the field tent shelters seemed quite satisfied with current tent shelters available to them, there is a need to conduct aperiodic systematic postoccupancy evaluation of shelters from the users' perspective so as to integrate user input into the design and deployment of the shelters. The percentage of those who experienced one problem or another is not so trivial that it should be ignored.

The study was limited in a number of ways, and additional research is needed to provide a better living and working environment for those who have to rely on temporary field tent shelters in polar regions. First, user responses collected in this study were based on recollection and memory, which might be less than accurate and valid. An on-site, in-time collection of responses from polar teams while they are working in the field will surely yield information better reflecting users' experiences and evaluations of the field tent shelters. 
Second, issues related to the well-being of users, such as depression, performance, and mood changes, can benefit from a longitudinal collection of data from respondents instead of the onetime collection adopted by this study. Many environmental behavioral studies report that collecting information on a periodic basis over time is not only appropriate but even necessary.

Finally, the size of the respondent sample is not large enough to conduct a comprehensive analysis and to provide conclusions of greater statistical significance. A future onsite study of a larger sample will help add necessary validity to results.

\section{References}

ASA. (1991, May). Comparison report on portable field camp structure. Englewood, CO: Antarctic Support Associates.

Brier, F. W. (1969). Polar camp improvements-Structural, architectural, and utility accessories for the Jamesway shelter. Port Hueneme, CA: U.S. Civil Engineering Laboratory.

Byrne, D., Barry, J., \& Nelson, D. (1963). Relation of the revised repression-sensitization scale to measures of self-description. Psychological Reports, 13, 323-334.

Carrere, S. (1990). Physiological and psychological patterns of acute and chronic stress during winter isolation in Antarctica. Unpublished doctoral dissertation, University of California, Irvine.

Carrere, S., \& Evans. G. W. (1994). Life in an isolated and confined environment: A qualitative study of the role of the designed environment. Environment and Behavior, 26, 707-741.

Chinn, E. J. (1983). The development of mobile field units by British Antarctic Survey. In Proceedings of Scientific Committee on Antarctic Research, 3, 557-572.

Derogatis, L., Lipman, R., Rickels, K., Uhlenhuth, E., \& Covi, L. (1974). The Hopkins symptom checklist (HSCL): A self-report symptom inventory. Behavioral Science, 19, 1-15.

Flanders, S. N. (1980). Cold regions testing of an airtransportable shelter. Hanover, NH: Cold Regions Research and Engineering Laboratory.

Floyd, P. (1974). The North Slope Center: How was it built? Northern Engineer, 6 (3), 22-35.

Johnson, P. R. (1970). The IAEE prefabricated hut. College: Institute of Arctic Environmental Engineering, University of Alaska.

Kovacs, J. M. (1981). Modular heliportable shelter system for small camps. In T. S. Vinson (Ed.), Specialty conference on the Northern Community: A search for a quality environment (pp. 313332). New York: American Society of Civil Engineers.

Ledingham, R. B., \& Keage, P. L. (1986). New portable shelters for polar use. Northern Engineer: 18 (1), 28-31. 
Leon, G. R. (1991). Individual and group process characteristics of polar expedition teams. Environment and Behavior, 23, 723-748.

Mackay, C., Cox, T., Burrows, G., \& Lazzerini, T. (1978). An inventory for the measurement of selfreported stress and arousal. British Journal of Social Psychology, 17, 283-284.

Marans, R., \& Spreckelmeyer, K. (1981). Evaluating Built Environments: A behavioral approach. Ann Arbor: University of Michigan Press.

Mocellin, J.N. P., \& Suedfeld, P. (1991). Voices from the ice: Diaries of polar explorers. Environment and Behavior, 23, 704-722.

Natani, K., \& Shurley, J. T. (1979). Sociopsychological aspects of a winter vigil at Pole Station. In E. K. E. Gunderson (Ed.), Human adaptability to Antarctic conditions (Antarctic Research Series 22, pp. 89-114). Worcester, MA: Heffernan.

NCEL. (1991). Lightweight mobile work shelter for cold weather and remote sites. Port Hueneme, CA: Naval Civil Engineering Laboratory.

Oakley, E. N. H. (1986). First Antarctic winter in tents: The Joint Services Expedition to Brabant Island. .Journal of the Royal Naval Medical Services, 72, 69-74.

Palinkas, L. A. (1991). Effects of physical and social environments on the health and wellbeing of Antarctic winterover personnel. Environment and Behavior, 23, 782-799.

Preiser, W. F. E., Rabinowitz, H. Z., \& White, E. T. (1988). Post occupancy evaluation. New York: Van Nostrand Reinhold.

Richter, D. L. (1979, January-February). South Pole dome revisited. Military Engineer, pp. 2-5.

Steel, G. D., E Suedfeld, P. (1991). Temporal patterns of affect in an isolated group. Environment and Behavior, 3, 749-765.

Suedfeld, P. (1987). Extreme and unusual environments. In D. Stokols \& I. Altman (Eds.), Handbook of environmental psychology (pp. 863887). New York: John Wiley.

Suedfeld, P. (1991). Polar psychology: An overview. Environment and Behavior, 23, 653-665.

Ursin, H., Bergan, T., Collet, J., Endersen, I. M., Lugg, D. J., Maki, P., Matre, R., Molvær, O., Muller, H. K., Olff, M., Pettersen, R., Sandal, G. M., Vaænes, R., \& Warncke, M. (1991).Psychobiological studies of individuals in small, isolated groups in the Antarctic and in space analogues. Environment and Behavior, 23, 766-781 